\title{
Motivating And Managing Generation X And Y On The Job While Preparing For Z: A Market Oriented Approach
}

Patrick J. Montana, Fordham University, USA Francis Petit, Fordham University, USA

\begin{abstract}
This article examines the factors that have motivated Generation $X$ and $Y$ over time and the emerging attributes that will be impacting Generation $Z$. More specifically, two hundred recent graduates and Executive MBA students (Generation $X$ ) as well as undergraduates (Generation $Y$ ) at Fordham University Schools of Business were surveyed recently and were asked to rank six (out of twenty five) factors they consider most important in motivating them to do their best work on the job. When comparing Generation $X$ and Generation $Y$, the results are very similar. Both groups rank Respect for me as a person and Good Pay to be their top motivators. While both groups have similar motivators in their top six including Chance for promotion, Opportunity to do interesting work and Opportunity for self-development and improvement, Generation $Y$ differs greatly as Getting along well with others on the job ranked third in their top six. This factor is considered a "hybrid factor" that crosses motivation and maintenance needs. While this "hybrid factor" does not appear as an important motivator among the Baby Boom generation, it is projected that Getting along well with others on the job will be a critical factor especially among Generation $Z$ for a variety of reasons predominately their technical background.
\end{abstract}

ompared to earlier generations in the work force, Generations $\mathrm{X}$ and $\mathrm{Y}$ are still motivated more by the prospect of steady employment and a chance for promotion, but getting along well with others on the job has surfaced as a key motivator for Generation Y.

These were the findings of a 2007 survey, conducted by the authors of 200 recent graduates and Executive MBA students (Generation X) and current undergraduates (Generation Y) of Fordham University Schools of Business. The students who participated in the study were asked to rank the six (of 25) factors they consider most important in motivating them to do their best work. (See Figure 1.) The results were compared with the rankings by two groups of business executives, including baby boomers and pre-boomers.

Column A in Figure 1 indicates the rankings by 6,000 managers who were surveyed during a conference in the early 1970s. ${ }^{1}$ The managers ranked the following six employment conditions as their principal motivators in the workplace.

1. Respect for me as a person

2. Good pay

3. $\quad$ Opportunity to do interesting work

4. Opportunity for self-development and improvement

5. Large amount of freedom on the job

6. Feeling my job is important

Now compare these results with Column B, the rankings by 500 representatives of different companies and government agencies, who were attending a university executive development program in the mid-1980s. The factors they considered key motivators are as follows: 
1. Respect for me as a person

2. Good pay

3. Opportunity to do interesting work

4. Feeling my job is important

5. Opportunity for self-development and improvement

6. Large amount of freedom on the job

Figure 1

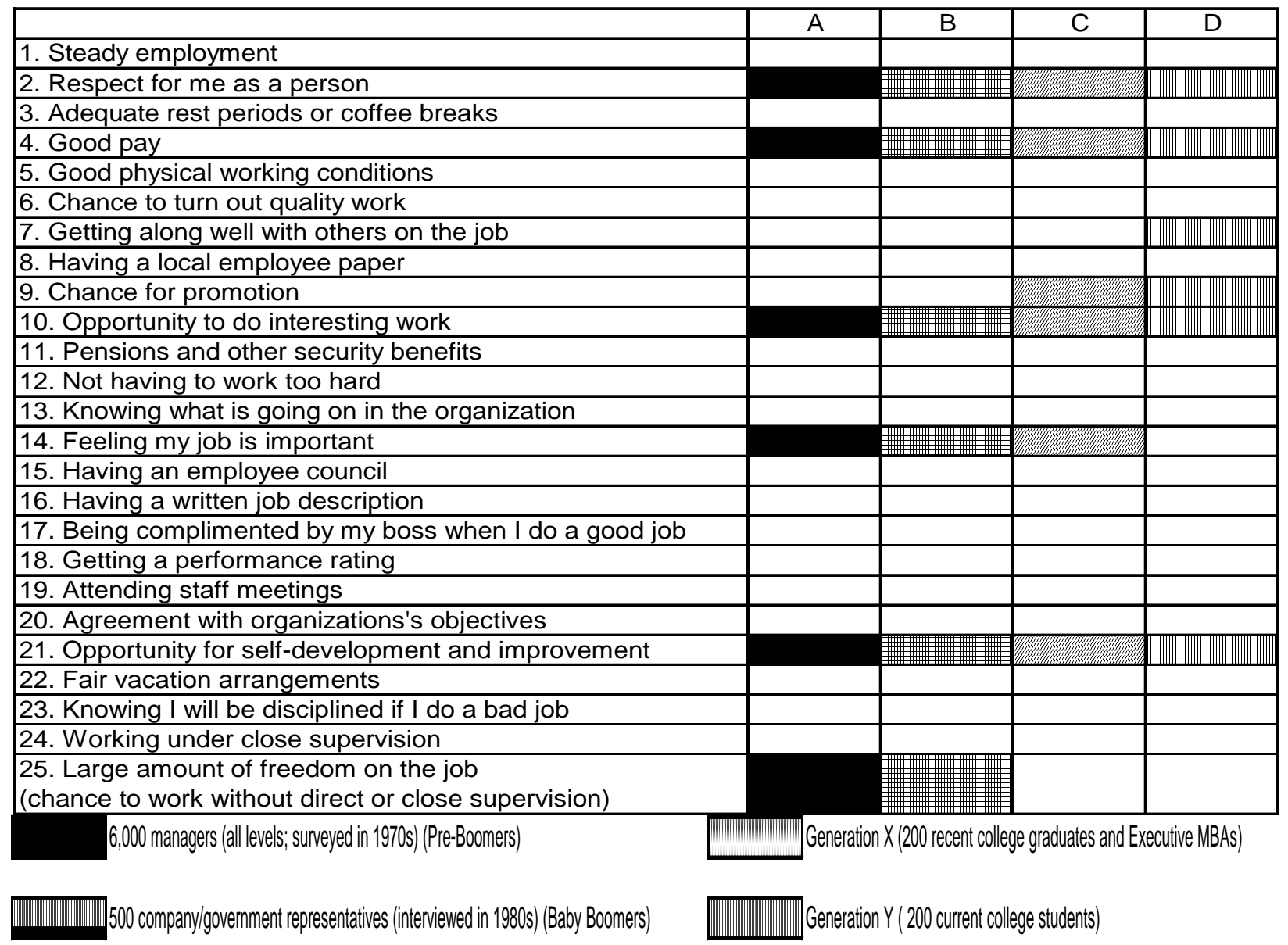

It's remarkable how these two groups parallel one another. But, the rankings aren't consistent across generational lines as the survey of Generations $\mathrm{X}$ and $\mathrm{Y}$ reveals. They ranked the following six factors as their principal motivators. (See Columns C and D.)

Generation X

1. Respect for me as a person

2. Good pay

3. Chance for promotion

4. Opportunity to do interesting work

5. Feeling my job is important

6. Opportunity for self-development and improvement 


\section{Generation Y}

1. Respect for me as a person

2. Good pay

3. Getting along well with others on the job

4. Chance for promotion

5. Opportunity to do interesting work

6. Opportunity for self-development and improvement

Although the rankings by Generations $\mathrm{X}$ an $\mathrm{Y}$ were markedly different from earlier generations, they were close to each other.

These young men and women can command relatively good salaries, and they are interested in receiving them. Pay matters to them, not only for economic reasons but also as a symbol of their worth and status. A chance for promotion also is important to them, as is steady employment, a factor very much on their minds, which ranked a close seventh on their list of motivators.

\section{MOTIVATORS VS. MAINTENANCE FACTORS}

In his "Two Factor Theory of Motivation," psychologist Frederick I. Herzberg distinguished the factors in the workplace that motivate people (satisfiers) from the maintenance factors, which have the potential to dissatisfy them. ${ }^{2}$

According to Herzberg, motivation develops from the challenge of the job- through achievement, recognition, the work itself, responsibility, advancement, and growth. Dissatisfaction, if any, results from the maintenance factors, which represent those lower-level needs that employees assume will be adequately met. A good boss and good working conditions are examples of such needs. Few managerial or professional people would say these job factors motivate them most. Yet, the minute a boss or working conditions becomes a principal concern, factors such as interesting job content and opportunity for advancement lose their power to motivate. In short, effective job performance depends on the satisfaction of both motivation and maintenance needs.

An employee's motivation is, of course, affected by his or her age, personal circumstances, external environment, and the current phase of his or her life and career. For instance, "steady employment" and "good pay" often rank higher among all generations during times of economic uncertainty. When the economy is flourishing, employees tend to take these maintenance factors for granted; when unemployment and inflation are high, their principal motivators change.

Figure 2

Motivating and Demotivating

Factors in the Workplace

\begin{tabular}{|c|c|}
\hline $\begin{array}{c}\text { Motivators } \\
\text { (Satisfiers) }\end{array}$ & $\begin{array}{c}\text { Maintenance factors } \\
\text { (Dissatisfiers) }\end{array}$ \\
\hline Achievement & Organization policy and administration \\
\hline Recognition & Supervision \\
\hline Work itself & $\begin{array}{c}\text { Interpersonal relations } \\
\text { (with superiors, subordinates, and peers) }\end{array}$ \\
\hline Responsibility & Salary \\
\hline Advancement & Status \\
\hline Growth & Job security \\
\hline & Personal life \\
\hline
\end{tabular}




\section{THE HYBRID FACTOR}

In the authors' survey of Generations X and Y, "getting along well with others on the job" (factor 7) surfaced as the leading motivator of Generation Y respondents. It ranked higher than traditional motivators associated with these age groups such as "respect for me as a person," and "feeling my job is important," though these factors ranked in the top six.

Getting along well with others on the job would be listed as a hybrid factor, according to Herzberg. It has aspects of motivation and maintenance. If you cannot get along well with your boss, you will not be too motivated or satisfied, and if you cannot get along well with your subordinates or peers you will be dissatisfied on the job.

Wouldn't it make sense, then, for employers to create an environment in which the factors that motivate employees to achieve will outweigh the maintenance factors, the potential dissatisfiers, although both factors are conditions for motivation.

\section{IMPLICATIONS FOR MANAGEMENT}

Business Week on-line, describes Generation Y in this way, "born during a baby bulge that demographers locate between 1979 and 1994, they are as young as (13 and as old as 28) and at 60 million strong, more than three times the size of Generation X, they are the biggest thing to hit the American scene since the 72 million baby boomers. Still too young to have forged a name for themselves, they go by a host of taglines: Generation Y, Echo Boomers, or Millennium Generation. While boomers are still mastering Microsoft Windows, their kids are typing away at computers in nursery school. The Internet is their medium of choice",3

Carol Hymowitz of the Wall Street Journal reports that "motivating each of these generations to work together requires managers to relinquish a one-style fits-all approach to their subordinates"4. Understanding the factors that motivate each of these different groups is very important for managers to understand in order to manage effectively. Managers should endeavor to seek opportunities on the job for Generation Y employees to work more with others, whether in teams, on special projects, task forces or committees in order to develop their interpersonal skills, and reward them for effective performance in collaborative efforts. Moreover, more one-on-one coaching and counseling by managers with Generation Y employees may be necessary in selected situations. In this respect, it is interesting to note that among the Personal Competencies for Managerial Success recommended by the AACSBThe Association to Advance Collegiate Schools of Business International are:

- $\quad$ Leadership-the ability to influence others to perform tasks

- $\quad$ Analytical Thinking- the ability to interpret and explain patters of information

- Behavioral Flexibility- the ability to modify personal behavior to reach a goal

- Oral Communications-the ability to express ideas clearly in oral presentations

- Written Communications- ability to express one's ideas clearly in writing

- $\quad$ Personal Impact- the ability to create a good impression and instill confidence

Surely, these personal competencies all involve being able to get along well with others on the job.

\section{PREPARING GENERATION Z - THE NEXT GENERATION}

In a recent survey of Chief Information Officers (CIOs) of more than two hundred corporations, the question asked was: What are the top skills colleges and universities need to be teaching their students that they aren't now? ${ }^{5}$ The responses were:

- $\quad$ Communication/ People Skills

- $\quad$ Business Skills

- $\quad$ Real World/ Hands-on-Experience

- Troubleshooting 
- $\quad$ Project Management

- $\quad$ Analytical Skills

- Integration

These skills also require they are able to get along well with others on the job.

The American Management Association has defined management as working with and through other people in order to accomplish the objectives of the organization and its members. Taking an active role in its employees' career development is an effective way for an organization to meet these mutual expectations. If employees feel that an organization's investment in them is significant and continuous, they will enjoy a greater sense of job security, confident that the organization will be more likely to retain a resource in which it has a major investment. An organization will benefit greatly, not only by satisfying these motivators, but also by gaining a more committed and skilled work force. Increased employee competencies will also help the organization to maintain alignment with its mission.

$\mathrm{HR} /$ staffing professionals need only look at the effects of simultaneously downsizing and hiring, a practice many organizations have embraced despite its potentially adverse impact on the performance and productivity of organizations as a whole. Career planning and development, through effective management, can ensure that desired competencies will exist in the current and future work force and enable employers to reassign rather than replace talent. The savings realized in the process can, in turn, fund the organization's career planning and development initiatives.

\section{AUTHOR INFORMATION}

Patrick Montana is a professor of management at Fordham University's Schools of Business. He previously worked in key management positions in business (profit and non-profit) and government. He holds a Ph.D. in marketing from New York University and is the author of 25 books, including Conquering the Course: Nine Steps in Managing Your Business and Golf Expectations (John Wiley \& Sons), Stepping Out, Starting Over: How to Get Your Career and Life on the Right Track-Career Life Planning (McGraw Hill) and Management (Barron's $4^{\text {th }}$ Edition, 2008).

Francis Petit is the Assistant Dean and Director of Executive Programs at Fordham University Graduate School of Business Administration. In his overall work with executive students, Dr. Petit has established executive programs in North America, South America, Europe, Asia and the Middle East. He holds a doctorate in Economics and Education from Columbia University and serves as an Adjunct Professor of Marketing at Fordham University.

\section{Endnotes}

\footnotetext{
${ }^{1}$ This, Leslie E. and Lippitt, Gordon L. Work Motivation Checklist. IA:Development Publications.

${ }^{2}$ Herzberg, Frederick I. The Motivation to Work. 1959.

3 "Generation Y" by Ellen Newborne and Kathleen Kerwen. Business Week Online. February 13, 1999

4 "Managers Find Ways to Get Generations to Close Culture Gaps" Wall Street Journal. July 9, 2007.

5 “Job Skills: Preparing Generation Z." Computerweek. August 25, 2003.
} 
NOTES 